\title{
Comparison of Different Control Techniques for Interleaved DC-DC Converter
}

\author{
M. Kavitha ${ }^{1}$, V.Sivachidambaranathan ${ }^{2}$ \\ Department of Electrical and Electronics Engineering, Sathyabama Institute of Science and Technology
}

\begin{tabular}{l}
\hline \hline Article Info \\
\hline Article history: \\
Received Oct 23, 2017 \\
Revised Jan 18, 2018 \\
Accepted Feb 2, 2018 \\
\hline
\end{tabular}

\section{Keyword:}

Coupled inductor

DC-DC converter

Fuzzy logic controller

Interleaved

PI,PID

\begin{abstract}
Interleaved DC-DC converter with coupled inductor is used in standalone Photovoltaic, battery charger/discharger applications. The main issue of the Interleaved DC-DC converter is that, it does not provide constant output voltage for a change in input voltage. Therefore, the converter efficiency is reduced. Hence to overcome this drawback, proper controller has to be used. In this paper, different control techniques such as PI, PID and Fuzzy logic controller are used. The simulation was carried out using MATLAB/Simulink and the results were compared. Fuzzy logic controller provides better regulated output voltage with less settling time.
\end{abstract}

Copyright $₫ 2018$ Institute of Advanced Engineering and Science. All rights reserved.

\section{Corresponding Author:}

M.Kavitha,

Department of Electrical and Electronics Engineering,

Sathyabama Institute of Science and Technology,

Chennai-600119, Tamil Nadu,India.

Email: kaveem@gmail.com

\section{INTRODUCTION}

In renewable application such as Photovoltaic, ripple free output is required, therefore interleaving technique is used [1]. In intereleaved DC-DC converter, the current is shared and hence current stress of the switch is reduced [2]. By employing coupled inductor, the power handling capacity of the converter can be improved [3]-[4]. The DC-DC converter which is used in industrial application suffers input voltage variation. Thus different control techniques are used to provide proper output for variation in input voltage. PI and PID controllers can produce better output for linear systems [5]-[6]. But for non linear systems, FLC can be used [7]. Fuzzy Logic Controller (FLC) is used in many Engineering applications such as automobile, elevators, air conditioners, home appliances and in DC-DC converters [8]-[9]. Compared to other linear controllers, FLC presents better performance. Fuzzy logic is a heuristic approach method, therefore used for DC-DC converter which undergoes supply voltage disturbances and load disturbances. In [10], different control methods such as voltage control, current control, sliding mode control and Fuzzy logic control were compared. Different DC-DC converter control techniques were discussed in [11] and their advantage and disadvantages were also stated.

In most of the researches, the interleaved boost converter either uses PI or PID controller. In this paper different control techniques such as PI, PID and Fuzzy Logic Controller are used for Interleaved DCDC converter with coupled inductor which undergoes input voltage variation. Section 2 describes the operation of the interleaved DC-DC converter. Section 3 describes the different control techniques. Simulation results and comparison of all three control techniques were discussed in Section 4 and in Section 5 . 


\section{INTERLEAVED DC-DC CONVERTER WITH COUPLED INDUCTOR}

The interleaved DC-DC converter with coupled inductor is shown in Figure 1. The purpose of coupled inductor is to reduce the input current ripples and reduces the size and weight of the converter as the two inductors are magnetically coupled in single core. There are four modes of operation. In mode 1 , the switch $S_{1}$ and $S_{2}$ are ON. The two inductor currents linearly increase. In mode 2, the switch $S_{1}$ is ON and $S_{2}$ is OFF. The current through inductor $\mathrm{L}_{1}$ increases and $\mathrm{L}_{2}$ decreases. The voltage across output capacitor $\mathrm{C}_{3}$ is $\mathrm{V}_{\mathrm{c} 3}=\mathrm{V}_{\mathrm{cb} 1}+\mathrm{V}_{\mathrm{cal}}$. Mode 3 is same as mode 1. In mode 4, the switch $\mathrm{S}_{2}$ is $\mathrm{ON}$, therefore current through inductor $\mathrm{L}_{2}$ increases. The voltage across output capacitor $\mathrm{C}_{4}$ is $\mathrm{V}_{\mathrm{c} 4}=\mathrm{V}_{\mathrm{cb} 1}+\mathrm{V}_{\mathrm{ca} 1}$.

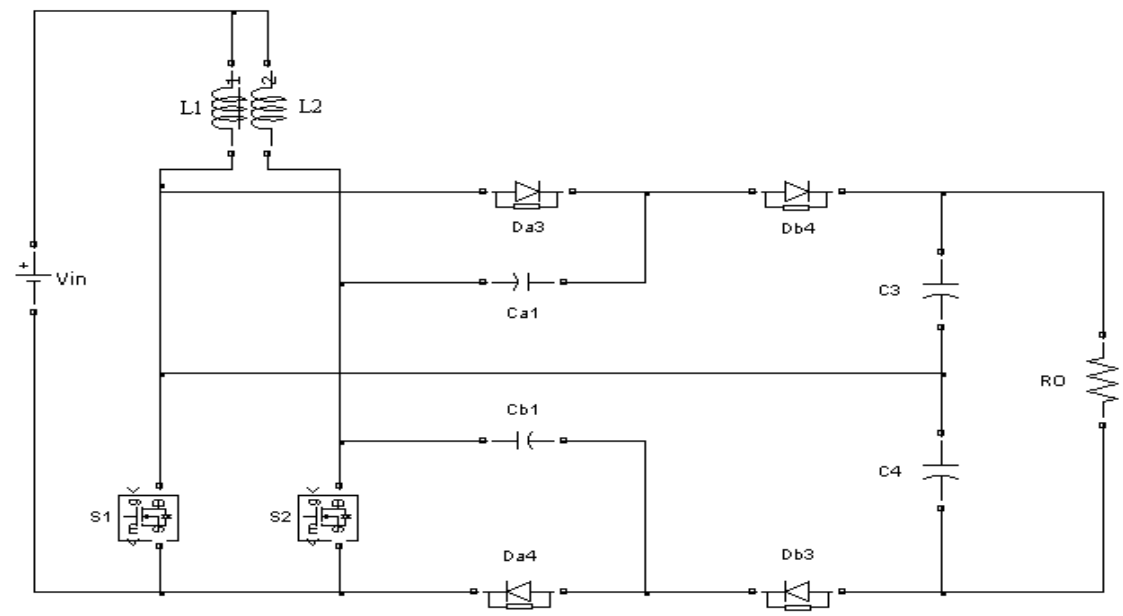

Figure 1. Interleaved DC-DC Converter with Coupled Inductor

\section{CONTROL TECHNIQUES} techniques.

The output voltage of the converter is maintained to a particular value by using different control

\subsection{PI Controller}

The output of the system is regulated by Proportional-Integral controller. In this controller, the output of the system is compared with the reference value and the resulting error signal is given to PI controller. Using Ziegler-Nichols method, the value of proportional and integral gain constant were determined. Future error of the system cannot be predicted using PI controller, hence the rise time of the system cannot be decreased and oscillation cannot be neglected.

$$
V_{o}(s)=\left(K_{p}+\frac{K_{i}}{s}\right) E(s)
$$

\subsection{PID Controller}

The derivative gain constant is included along with PI controller to eliminate or to reduce the overshoot. The derivative constant also reduces the oscillation of the output.

$$
V_{o}(s)=\left(K_{p}+s K_{d}+\frac{K_{i}}{s}\right) E(s)
$$

\subsection{Fuzzy Logic Controller}

Fuzzy logic controller requires linguistic rules. Detailed knowledge of the process to be controlled is required for framing the rules. Figure 2 shows the Fuzzy control block.FLC has four major blocks.

\section{Fuzzification}

The crisp inputs are converted into fuzzy inputs. The crisp inputs are the real inputs such as voltage, current, temperature, pressure measured by sensors. 


\section{Knowledge base}

It is a combination of rule base and database. Rule base uses set of IF..THEN rules. Database describes the membership functions that are used in fuzzy rules.

\section{Interference Engine}

This converts fuzzy input to fuzzy output by using set of IF.THEN rules.

Defuzzification

This block converts the fuzzy output to crisp output.

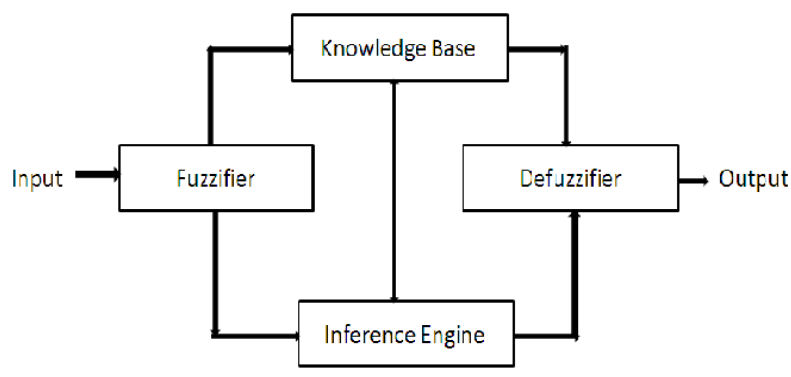

Figure 2. Fuzzy Control Block

\section{SIMULATION RESULTS}

The Interleaved DC-DC converter with coupled inductor is simulated using MATLAB software under open loop and closed loop. In closed loop, different control techniques such as PI, PID and FLC were used and the results are compared.

\subsection{Open Loop}

The Interleaved DC-DC converter coupled with inductor is subjected to input voltage variation under open loop condition. The component specification used in simulation is as follows: Blocking capacitor $\mathrm{C}_{\mathrm{a} 1}=\mathrm{C}_{\mathrm{a} 2}=10 \mu \mathrm{F}$, output capacitor $\mathrm{C}_{3}=\mathrm{C}_{4}=250 \mu \mathrm{F}$, Switching frequency $\mathrm{f}_{\mathrm{s}}=40 \mathrm{kHz}$. The input and the corresponding output voltage waveform is shown in Figure 3. Figure 4 shows the corresponding output power variation of the converter under open loop condition. Thus, when input voltage is $25 \mathrm{~V}$, the output of the converter is $400 \mathrm{~V}$ and output power is $400 \mathrm{~W}$. At $0.3 \mathrm{sec}$ when the input voltage is incremented by $5 \mathrm{~V}$, the output voltage increases to $480 \mathrm{~V}$ and the corresponding output power increases to $480 \mathrm{~W}$. Thus, under open loop condition, the output voltage of the converter is not regulated.

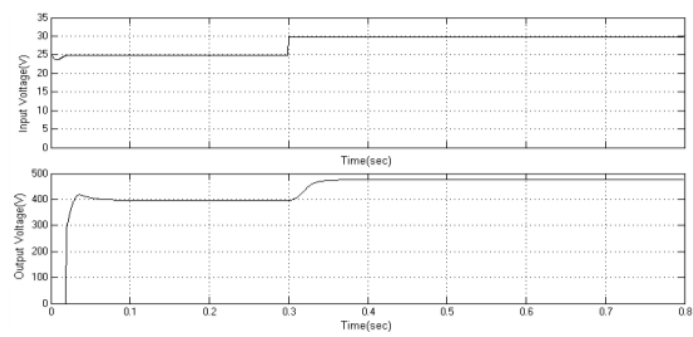

Figure 3. Input and Output Voltage Waveform of the Converter Under Open Loop

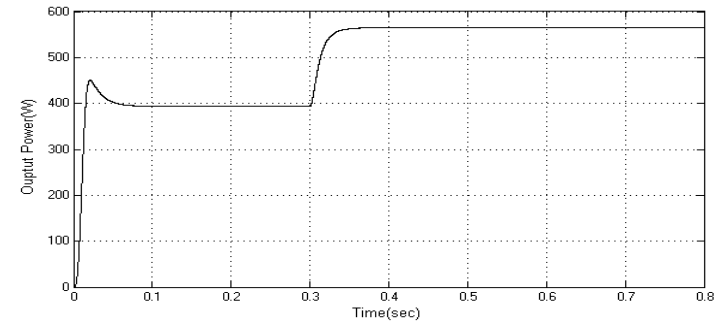

Figure 4. Waveform of Output Power of Converter under Open Loop

\subsection{PI Controller}

The output voltage of the converter is regulated by proportional integral controller. In this controller, the output voltage of the converter is compared with the set value and the resulting error signal is given to PI controller. Using Ziegler-Nichols method, the value of proportional gain constant and integral gain constant is obtained as 0.5 and 9 respectively. This controlled signal is given to produce pulse for the converter switch.Figure 5 shows the simulation circuit diagram of Interleaved Converter using PI controller. Figure 6 represents the input and output voltage waveform of the converter when PI controller is used. Figure 7 represents output power of the converter.It was found that using PI controller, the output voltage is regulated 
but with a overshoot of $32 \mathrm{~V}$ and output power with a overshoot of $60 \mathrm{~W}$. Using PI controller the settling time was found to be $t_{s}=0.62 \mathrm{sec}$ for which the output reaches steady state.

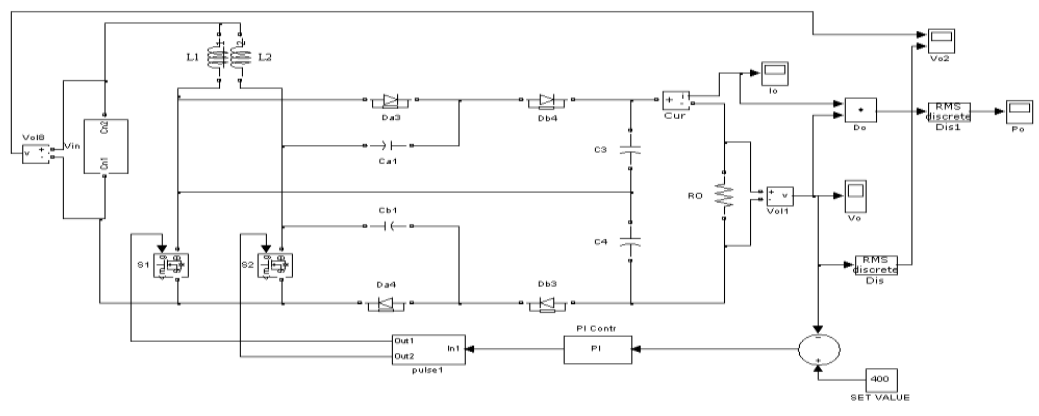

Figure 5. Simulation Circuit Diagram of Closed Loop Interleaved Converter using PI Controller.

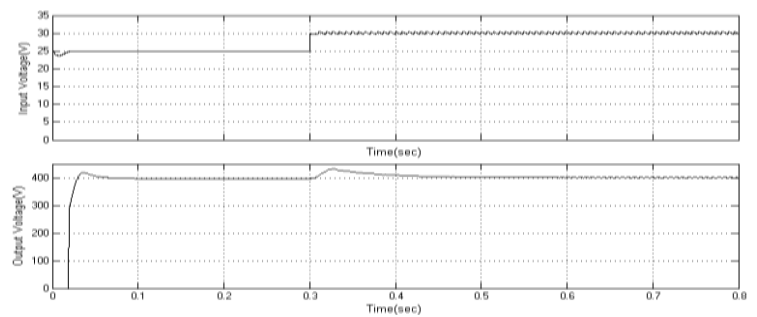

Figure 6. Input and Output Voltage Waveform of the Converter using PI Controller

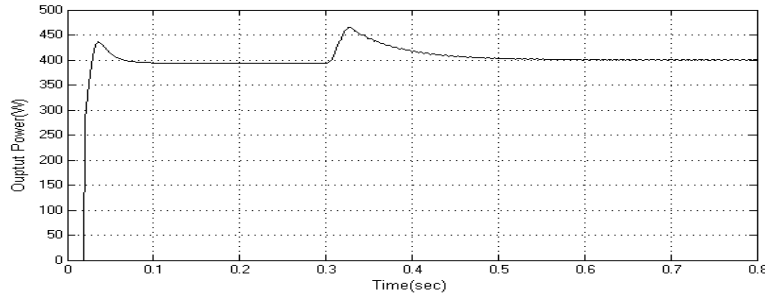

Figure 7. Output Power Waveform of the Converter using PI Controller

\subsection{PID controller}

The response signal of the converter is compared with set value and the error signal obtained is given to PID controller. The controller generates control signal which is used to produce the pulses to the switches. Using Ziegler-Nichols method, $\mathrm{K}_{\mathrm{p}}, \mathrm{K}_{\mathrm{i}}$ and $\mathrm{K}_{\mathrm{d}}$ value are obtained as 0.5, 9 and 0.02 respectively. Figure 8 shows the PID controller and PWM block. Figure 9 shows the input and output voltage waveform of the converter. Figure 10 shows the output power waveform of the converter.At $0.3 \mathrm{sec}$, when the input voltage is varied from $25 \mathrm{~V}$ to $30 \mathrm{~V}$, it was found that using PID controller, the output voltage is regulated but with a overshoot of $20 \mathrm{~V}$ and the output power with a overshoot of $40 \mathrm{~W}$. The settling time to reach steady state was found to be $0.6 \mathrm{sec}$.

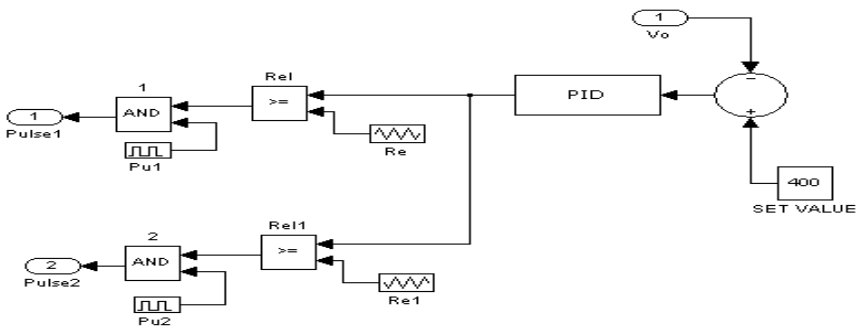

Figure 8. PID and PWM Block 

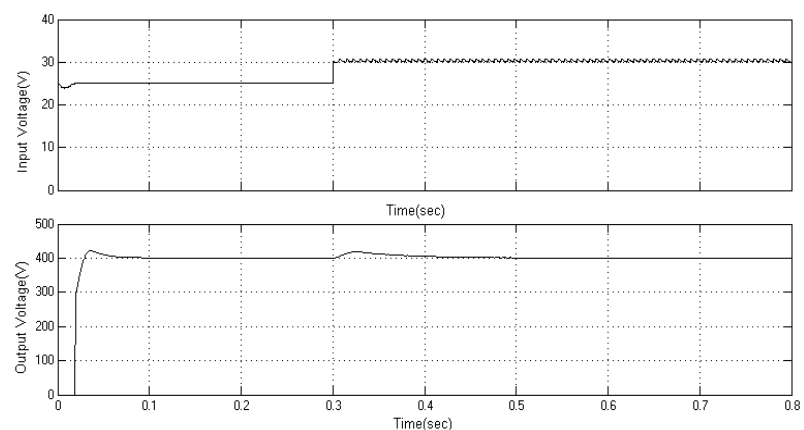

Figure 9. Input and Output Voltage Waveform of the Converter using PID Controller

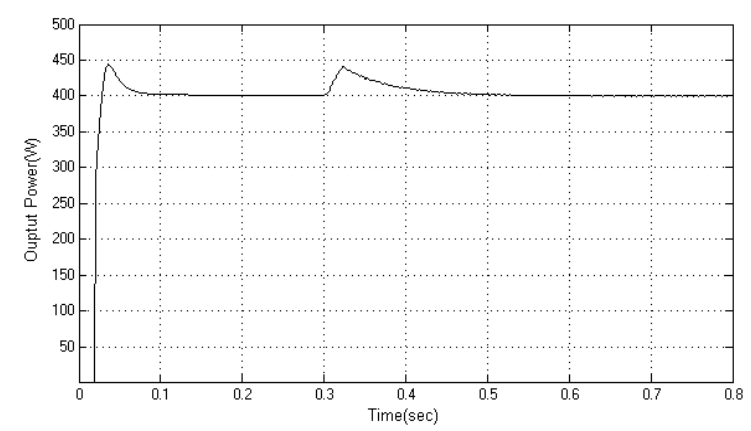

Figure 10. Output Power Waveform of the Converter using PID Controller

\subsection{Fuzzy Logic Controller}

For framing the linguistic rules, proper knowledge of the converter duty cycle is required. The following conditions have to be checked for fuzzy logic controller

1. If the response of the converter deviate more from the set value, then the duty cycle should be increased to bring the response to set value.

2. If the response is towards the set value, then duty cycle is slightly adjusted.

3. If the response is near to set value, then duty cycle is made constant

4. If the response is above the set value, then the duty cycle is made negative.

In fuzzification, two inputs namely error and change in error is fed. Error is the comparison of output voltage of the converter and set value.

$$
e(t)=V_{\text {ref }}-V_{o}(t)
$$

change in error,

$$
c e(t)=e(t)-e(t-1)
$$

Therefore, the change in error is the difference in present and past error. The error and change in error are represented as membership function in fuzzification. The membership functions used for input and output are NB, NS, ZE, PS, PB where NB=Negative Big, NS=Negative Small, ZE=Zero Equal, PS=Positive Small, $\mathrm{PB}=$ Positive Big.

Using membership function, certain rules are framed to get the output which decides the duty cycle of the switch and it is given in Table. 1

Table 1. Fuzzy Control Rules

\begin{tabular}{rlllll}
\hline $\mathbf{C E} / \mathbf{E}$ & NB & NS & ZE & PS & PB \\
\hline NB & NB & NB & NB & NS & ZE \\
NS & NB & NB & NS & ZE & PS \\
ZE & NB & NS & ZE & PB & PB \\
PS & NS & ZE & PB & PB & PB \\
PB & ZE & PS & PB & PB & PB \\
\hline
\end{tabular}

The Fuzzy logic control block is represented in Figure 11. Figure 12 shows the inputs and output of the controller which has proper membership function. The input and output voltage waveform of the converter is represented in Figure 13. The output power waveform of the converter is shown in Figure 14. It was found that using FLC, the output voltage and output power are regulated without any overshoot even when there is a input voltage disturbance. The settling time to reach the steady state is $0.04 \mathrm{sec}$. 


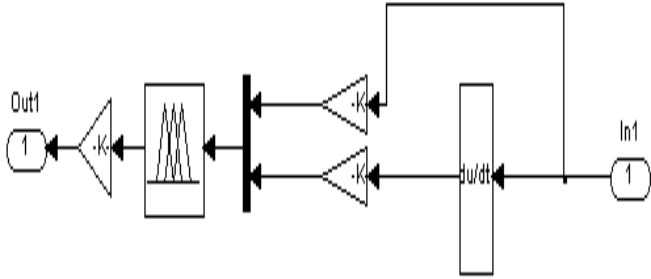

Figure 11. Fuzzy Logic Control Block
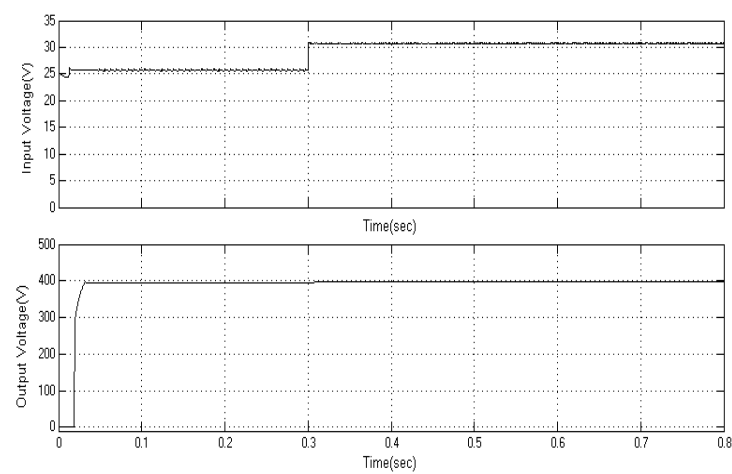

Figure 13. Input and Output Voltage Waveform of the Converter using FLC

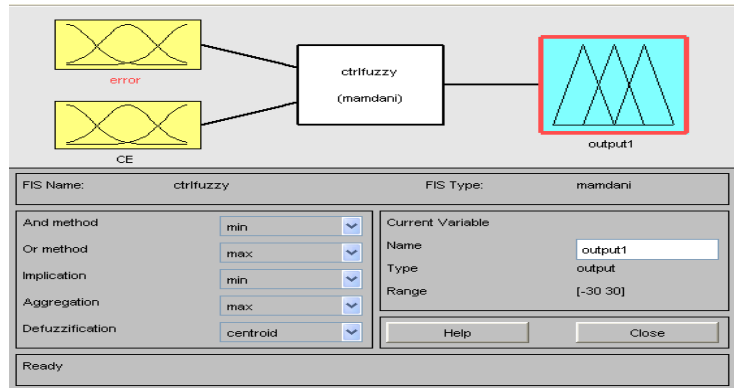

Figure 12. Inputs and Output of FLC

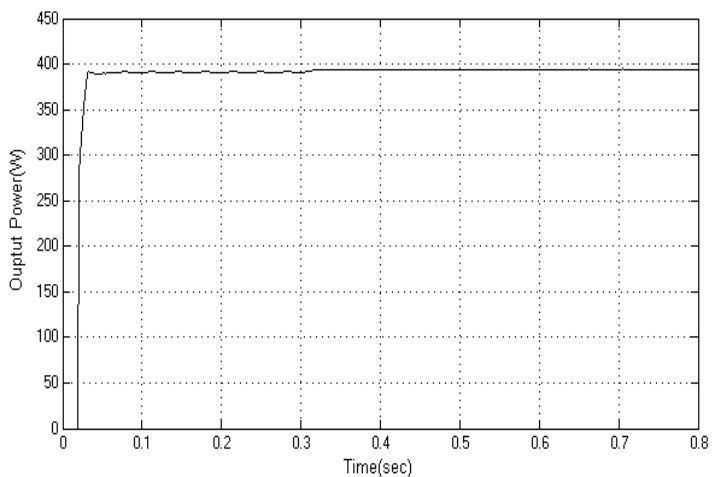

Figure 14. Output Power of the Converter using FLC

\section{CONCLUSION}

The interleaved DC-DC converter with coupled inductor is simulated under open and closed loop. In closed loop, the output voltage of the interleaved DC-DC converter with coupled inductor is regulated by different control techniques such as PI, PID and Fuzzy Logic when the input voltage is subjected to disturbances. With PI and PID controller, the output voltage is regulated but with a overshoot of $32 \mathrm{~V}$ and $20 \mathrm{~V}$ respectively. Using PI and PID controller the settling time of response is found to be $0.62 \mathrm{sec}$ and $0.6 \mathrm{sec}$ respectively. Fuzzy logic controller gives better output without any overshoot and with less settling time of $0.04 \mathrm{sec}$.

\section{REFERENCES}

[1] Ching-Tsai Pan,Chen-Feng,Chuang,Chia-Chi Chu., "A novel transformer-less adaptable voltage quadrupler DC converter with low switch voltage stress," IEEE Trans. Power Electron., vol. 29, no. 9, pp. 4787-4796, Sep.2014.

[2] M.Kavitha, V.Sivachidambaranathan, "Performance Analysis of Transformer-Less Two Phase Interleaved High Gain DC Converter using MPPT Algorithm,” Indian Journal of Science and Technology,Vol.8(15),July 2015

[3] M.Kavitha, Dr.V.Sivachidambaranathan, "PV based high voltage gain Quadratic DC- DC Converter integrated with coupled inductor," International Conference on Computation of Power, Energy Information and Communication (ICCPEIC'16),pp.607-612,April 2016.

[4] Sivachidambaranathan.V, "High Frequency Isolated Series Parallel Resonant Converter", Indian Journal of Science and Technology, Vol .18(15), pp 1-6,July 2015.

[5] Rohitash Singh,Saurabh Kr.Bajpai,Harinder Singh Sandhu, "Comparative Study of PWM Control and PI Control of Induction motor,” Bulletin of Electrical and Engineering and Infomatics, Vol.4,No.1,March 2015,pp.53-58.

[6] Vanitha D,M.Rathinakumar, "Fractional Order PID Controlled PV Buck Boost Converter with Coupled Inductor," International Journal of Power Electronics and Drive System, Vol.8, No.3, September 2017,pp.14011407.

[7] R.Balamurugan, R.Nithya,” FC/PV Fed SAF with Fuzzy Logic Control for Power Quality Enhancement,” International Journal of Power Electronics and Drive System, Vol.5, No.4, April 2015,pp.470-476.

[8] Meryem Oudda, Abdeldjebar Hazzab, "Photovoltaic System with SEPIC Converter Controlled by the Fuzzy Logic," International Journal of Power Electronics and Drive System, Vol.7, No.4, Dec 2016, pp.1283-1293. 
[9] B V Rajanna, Ganta Joga Rao,S.K Shrivstava, "Defining Control Strategies for Micro Grids Islanded operation with Maximum Power Point Tracking using a Fuzzy Logic Control Scheme,” International Journal of Power Electronics and Drive System, Vol.7, No.3, September 2016,pp.723-733.

[10] N. S K Sastry, Dr. S. Pattnaik" "Reduction of Ripple in a single phase buck converter by Fuzzy logic control", International Journal of Engineering Research and Applications (UERA), May-Jun 2012,Vol. 2(3), pp.2202-2204.

[11] S.Verma, S.K Singh, "Overview of control Techniques for DC-DC converters", Research Journal of Engineering Sciences, August 2013, Vol.2(8), pp.18-21.

\section{BIOGRAPHIES OF AUTHORS}

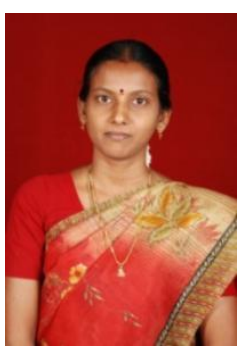

M.Kavitha has received her B.E degree in Electrical and Electronics Engineering from Bharathiyar University, Tamilnadu, India in 2000 and M.E degree in Power Systems Engineering from Anna University, Tamilnadu, India in 2012. She is pursuing her Ph.D under the faculty of Electrical and Electronics Engineering at Sathyabama Institute of Science and Technology from 2014. Her research interest includes Renewable Energy sources, Energy storage system, Fuzzy logic controller, Artificial Neural network and Power Electronic Converters.

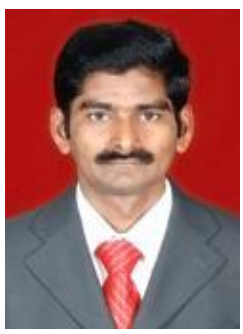

Dr.V.Sivachidambaranathan received his M.E. degree in Power Electronics and Industrial Drives from Sathyabama Institute of Science and Technology, Chennai in 2005 and obtained his Ph.D. degree in the Faculty of Electrical Engineering from Sathyabama University, Chennai in the year 2013. He is currently working as Associate Prof. and Head of the Department of Electrical and Electronics Engineering, Head - Internal Exam Cell, at Sathyabama Institute of Science and Technology, Chennai. His research interest includes power converter, drives and control and renewable energy sources. 